\title{
CORRELATION BETWEEN CHROMOPHORE IMPURITY CONTENT AND FIRED COLOUR DATA OF KAOLIN CLAY
}

\author{
PARVESH AGRAWAl \\ Central Glass \& Ceramic Research Institute, 168-169, Naroda Industrial Estate, Naroda, \\ Ahmedabad, Gujarat 382330, India. \\ parvesh@cgcri.res.in \\ S. N. MISRA \\ Central Glass \& Ceramic Research Institute, 168-169, Naroda Industrial Estate, Naroda, \\ Ahmedabad, Gujarat 382330, India. \\ snmisra@cgcri.res.in
}

\section{T. SHARMA}

Department of Fuel and Mineral Engineering, ISM University Dhanbad Dhanbad, Jharkhand.India

hodfmeism@yahoo.co.in

\begin{abstract}
Different kaolin clay specimen exhibit varying colours after firing depending upon the relative presence of different mineral impurities, physical state of mineral constituents etc. Spectrophotometers used for determining colour values generate many sets of colour data. Interpretation of such colour values is a subjective matter. Increase in darkness, yellowness etc as a consequence of increase in chromophore impurity content in kaolin clay have been shown. However, the inverse of above ie; gradual change in colour values along with gradual change in chromophore impurity content over a realistic range has not been studied. Whether the colour data of kaolin clay after firing can be taken up as a function of impurity content needs to be investigated. Thus, to identify the correlation between kaolin clay impurity content and it's fired colour data the present investigation examined the hypotheses i) The colour development after firing of kaolin clay is an indicator of chromophore impurity content present therein and ii) All the colour variables (L, a, b, ISO2470, redness) constituting a colour data set of pressed kaolin clay specimen after firing will vary in similar manner such that to represent variation in impurity content. The study indicated that the colour values obtained by spectrophotometry of clay specimens after firing represent the chromophore impurity present therein in a less reliable manner. To relatively estimate the quantity of chromophore impurity present in a clay sample from its fired colour, the sample should be mixed with $50 \%$ by weight of potash feldspar, pressed in to tablet suitable for colour measurement and fired at or above $1220^{\circ} \mathrm{C}$ to vitrify. After that the 'L', 'a' and 'ISO2470' values obtained truly represent the chromophore present therein.
\end{abstract}

Keywords: Kaolin; Spectrophotometry; Fired colour.

\section{Introduction}

The basic structure and composition of ceramic have an influence on the way light interacts with them. Clay based ceramic bodies e.g.; porcelain contains small crystals 
embedded in glassy matrix. The relative amount of crystals and glass depends upon the process of preparation including composition of the mix. The relative amount of all the present phases crystal glass and pores and their morphology coupled with physical properties of constituent phases contribute to overall colour of ceramic. ${ }^{1}$

Different kaolin clay specimens exhibit varying fired colours depending upon the relative presence of different mineral impurities, physical state of mineral constituents, firing temperature etc in them. Spectrophotometers used for determining colour values generate many sets of colour data. Interpretation of such colour values is a subjective matter. Researchers have shown increase in darkness, yellowness etc as a consequence of increase in chromophore impurity content in kaolin clay. ${ }^{2-4}$ However, the inverse of above ie; gradual change in colour values along with gradual change in chromophore impurity content over a realistic range has not been studied. Whether the colour data of kaolin clay after firing can be taken up as a function of impurity content needs to be investigated. To identify the correlation between kaolin clay impurity content and it's fired colour data, and fix up the appropriate experimental conditions for determination of fired colour of kaolin clay, an investigation has been carried out to examined the hypotheses; 1) The colour development after firing of kaolin clay is an indicator of chromophore impurity content present therein, 2) All the colour variables (L, a, b, ISO2470, redness) constituting a colour data set of pressed kaolin clay specimen after firing will vary in similar manner such that to represent variation in impurity content.

\section{Experimental}

\section{Materials and Methods}

About 500 grams of low grade china clay SR, which is high in chromophore minerals, was pulverised and powdered material was blunged in water keeping $10 \%$ solid concentration and $0.5 \%$ sodium hexameta phosphate on weight basis of clay was added as dispersant. The clay was dispersed with the help of an electrical stirrer (200rpm). The thoroughly dispersed slip was passed through $53 \mu$ (300 mesh) sieve and the $-53 \mu$ fraction was obtained. The material retained on the sieve discarded. The slip was dewatered and dried. The $-53 \mu$ fraction was further subjected to a high shear treatment to separate fine grained chromophore impurities and kaolin platelets in a laboratory model high shear mixer rotating at $2000 \mathrm{rpm}$. The high shear treatment was carried out at $65 \%$ solid concentration, $0.4 \%$ addition of sodium silicate dispersant and for 4 minutes duration. Then the treated slurry was diluted with tap water to attain solid concentration of $10 \%$. The slurry was allowed to stand undisturbed for 10 minutes and coarse, heavy impurities were allowed to settle. Then, the clay suspension on the top was decanted and settled impurities in the bottom were collected separately. This process of separating impurity fraction repeated until there remained no traces of impurities. Both the fractions dewatered, dried and reserved for further experiments. The chromophore impurity fraction was incorporated in purified kaolin clay fraction in gradually increasing amount as given in Table 1 and total nine numbers of batches were obtained. 
Table 1: Controlled addition of chromophore impurity fraction in purified kaolin clay fraction

\begin{tabular}{lccccccccc}
\hline Batch No. $\Rightarrow$ & I & A & B & C & D & E & F & G & J \\
\hline $\begin{array}{l}\text { Purified clay } \\
\text { fraction, wt. \% }\end{array}$ & 100 & 90 & 80 & 70 & 60 & 50 & 40 & 30 & 0 \\
\hline $\begin{array}{l}\text { Impurity } \\
\text { fraction, wt. \% }\end{array}$ & 0 & 10 & 20 & 30 & 40 & 50 & 60 & 70 & 100 \\
\hline
\end{tabular}

All the nine batches were divided in to two parts and one part of each mix was further mixed with equal amount of potash feldspar, (1:1 ratio). All the 'clay only' batches and 'clay and feldspar' batches were mixed thoroughly and homogenised by dispersing in sufficient water, drying up to $7 \%$ moisture content and making dust for pressing. The dust was pressed uniaxially to form a tablet of $10 \mathrm{~mm}$ dia and $5 \mathrm{~mm}$ thickness in a manually operated laboratory model hydraulic press at $5 \mathrm{~kg} \mathrm{~cm}-2 \mathrm{sp}$ pressure. The pressed and dried tablets were fired at $1180^{\circ} \mathrm{C}, 1200^{\circ} \mathrm{C}, 1220^{\circ} \mathrm{C}, 1240^{\circ} \mathrm{C}$ and $1260^{\circ} \mathrm{C}$ in an electric kiln heated at $10^{\circ} \mathrm{C}$ per minute rate with dwelling of 15 minutes at peak firing temperature.

The SR purified clay and impurity fractions were characterised for complete chemical analysis, $\mathrm{X}$ ray powder diffraction (XRD), approximate mineralogical constituents were calculated by rational analysis, Particle size distribution, FTIR analysis, Thermo gravimetric and differential thermal analysis as per standard procedures. The optical properties ie; L,a,b in ISO units, ISO2470 whiteness index and redness were measured by spectrophotometer.

\section{Result and Discussion}

The chemical analyses of SR $(-53 \mu)$, high shear treated purified clay SR (HSPC) and its impurity fractions (HS-IMP) and feldspar are presented in Table-2. The XRD, DTA and

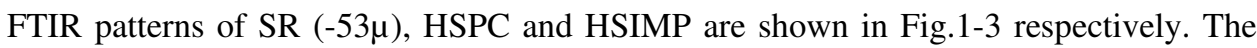

Table 2: Chemical Analysis of Different Clay Fractions and Feldspar

\begin{tabular}{|c|c|c|c|c|}
\hline Clay Fractions $\Rightarrow$ & SR $(-53 \mu)$ & HSPC & HS- IMP & Feldspar \\
\hline $\mathrm{SiO}_{2}$ & 47.40 & 45.33 & 52.06 & 66.54 \\
\hline $\mathbf{A l}_{2} \mathbf{O}_{3}$ & 35.60 & 36.77 & 30.97 & 18.68 \\
\hline $\mathrm{Fe}_{2} \mathrm{O}_{3}$ & 1.17 & 0.72 & 0.95 & 0.36 \\
\hline $\mathrm{TiO}_{2}$ & 2.71 & 2.07 & 2.96 & 0.05 \\
\hline $\mathrm{CaO}$ & 0.11 & 0.6 & 0.6 & 1.12 \\
\hline MgO & 0.12 & 0.08 & 0 & 0.08 \\
\hline $\mathrm{K}_{2} \mathrm{O}$ & 0.50 & 0.19 & 0.43 & 10.03 \\
\hline $\mathrm{Na}_{2} \mathrm{O}$ & 0.14 & 0.19 & 0.17 & 2.85 \\
\hline LOI & 11.99 & 14.05 & 11.86 & 0.29 \\
\hline
\end{tabular}




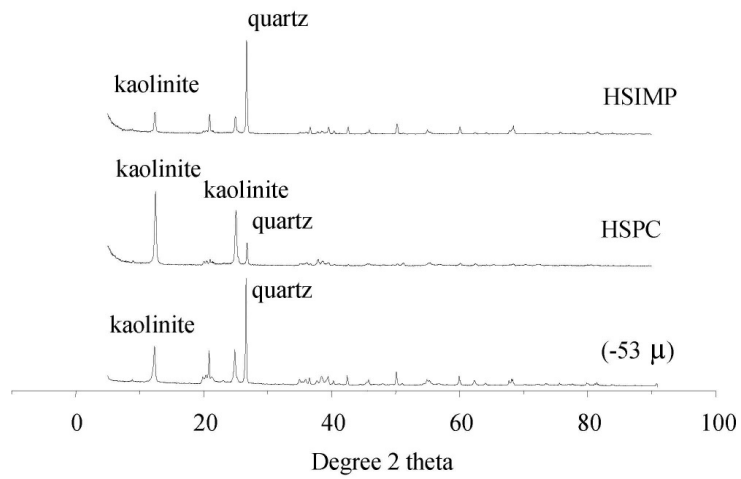

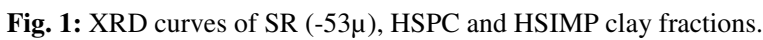

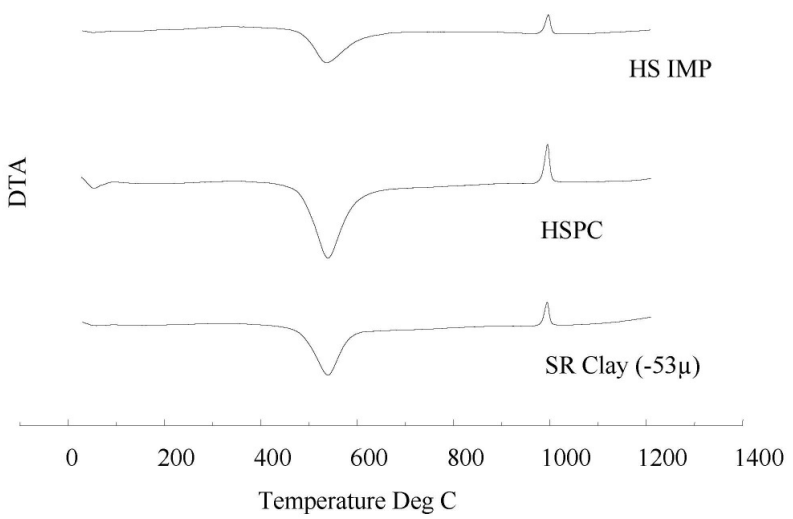

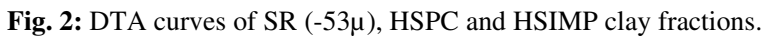

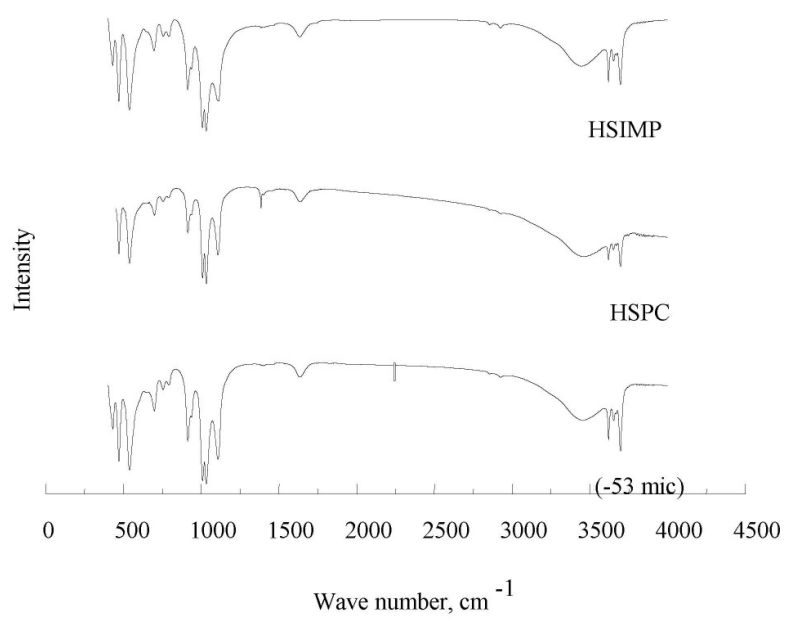

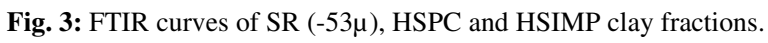


XRD pattern of SR $(-53 \mu)$ clay fraction shows sharp peaks at $d=7.13,3.57,2.56,2.28$, 1.67 and $1.54 \AA$ due to kaolinite and $d=3.34,4.25 \AA$ due to quartz. Strong peaks at $d=$ $3.57,2.38$ and $1.89 \AA$ are due to anatase. Three weak bands at $d=4.17,3.84$ and $1.78 \AA$ are due to Haematite / siderite as the major iron bearing impurity.

The DTA curves of SR $(-53 \mu)$, HSPC and HSIMP exhibited characteristic endothermic and exothermic peaks of kaolinite at around $540^{\circ} \mathrm{C}$ and $995^{\circ} \mathrm{C}$ respectively. Comparing with theoretical value of dehydroxylation weight loss of kaolinite; $13.9 \%$ with that of SR $(-53 \mu)$, it appears to be moderately contaminated with non clay matter. Area under the dehydroxylation curve at around $540^{\circ} \mathrm{C}$ indicates the relative quantity of kaolinite. The same was in the order of HSPC $>$ SR $(-53 \mu)>$ HSIMP. The primary mullite peak shifting to the lower temperature by $1^{\circ} \mathrm{C}$ in $\mathrm{HSPC}$ is attributed to higher reactivity through finer particle size distribution.

Based on mineral identified by XRD, TG/DTA and chemical analysis, the quantitative estimation of mineral constituents in the four clay fractions was carried out by norms method and presented in Table 3 . The kaolinite content has gradually increased from $88.41 \%$ in SR $(-53 \mu)$ to $91.79 \%$ in HSPC. The free silica content reduced from $3.63 \%$ in SR $(-53 \mu)$ to $0.77 \%$ in HSPC. It is evident that through high shear treatment the clay is efficiently separated from non clay matter and chromophore impurities. The particle size analysis of the three clay fractions (Fig.4) revealed that the concentration of

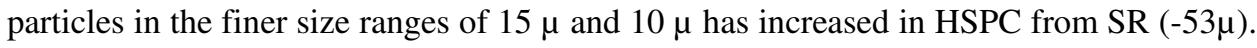
Based on $0.77 \%$ free silica and $91.79 \%$ kaolinite content (rational analysis), the HSPC is considered pure clay. Its particle size distribution showed all the particles to be below $10 \mu$ in size. Hence it is inferred that impurity content of free silica, haematite and anatase etc are more concentrated in the size range of $10 \mu$ to $36 \mu$.

The chemical analysis and rational analysis of all the experimental batches was calculated and the five colour variables were plotted against Kaolinite content, Haematite content and rutile content for both the 'clay only' and 'clay and feldspar' specimens. The variation of colour variables with respect to variation in kaolinite content and chromophore impurity content on a linear scale was observed. For clay only specimens, plot of ' $\mathrm{L}$ ' versus kaolinite content showed $\mathrm{R}^{2}$ (confidence level) values greater than $90 \%$

Table 3: Rational analysis of different clay fractions and feldspar

\begin{tabular}{lllll}
\hline Clay Fractions & SR $(-\mathbf{5 3} \boldsymbol{\mu})$ & HSPC & HS- IMP & Feldspar \\
\hline Kaolinite & 88.41 & 91.79 & 76.53 & 7.94 \\
\hline Quartz & 3.63 & 0.77 & 13.80 & 7.89 \\
\hline Feldspar & 4.15 & 2.73 & 3.98 & 81.70 \\
\hline Calcite & 0.20 & 1.07 & 1.07 & 1.96 \\
\hline Magnesite & 0.25 & 0.17 & 0.00 & 0.17 \\
\hline Rutile & 2.72 & 2.07 & 2.96 & 0.05 \\
\hline Haematite & 1.17 & 0.72 & 0.95 & 0.35 \\
\hline Carbonaceous & 0.54 & 0.68 & 0.71 & 0.00 \\
\hline
\end{tabular}




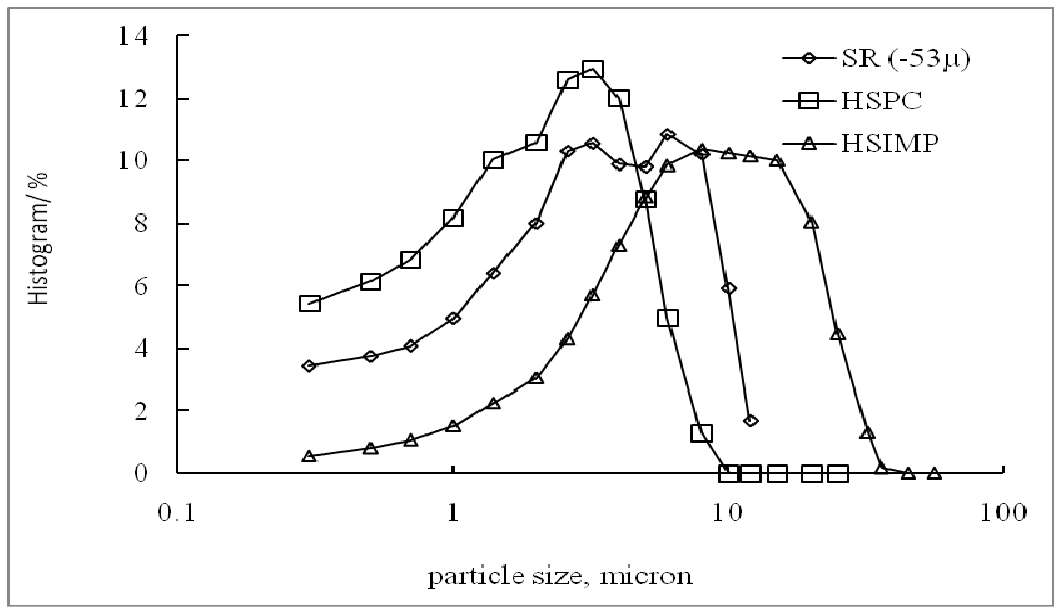

Fig. 4: Particle Size Distribution of Different Clay Fractions

at $1260^{\circ} \mathrm{C}$ (Fig. 5). All other plots either showed no specific trend or lesser than $90 \%$ confidence level. It has been reported in case of brightness of calcined kaolin that the calcinations temperature influences the solubility of iron and the brightness and reactivity of metakaolin. ${ }^{5}$ The brightness of kaolin changes during firing. From about $350^{\circ} \mathrm{C}$ to $800^{\circ} \mathrm{C}$ the brightness is reduced generally however in case of kaolin without free $\mathrm{Fe}_{2} \mathrm{O}_{3}$, it is remains reduced up to $500^{\circ} \mathrm{C}$ only. Above these temperatures, the brightness increases with the firing temperature under oxidising conditions because of iron going into structure of the phase. ${ }^{6}$

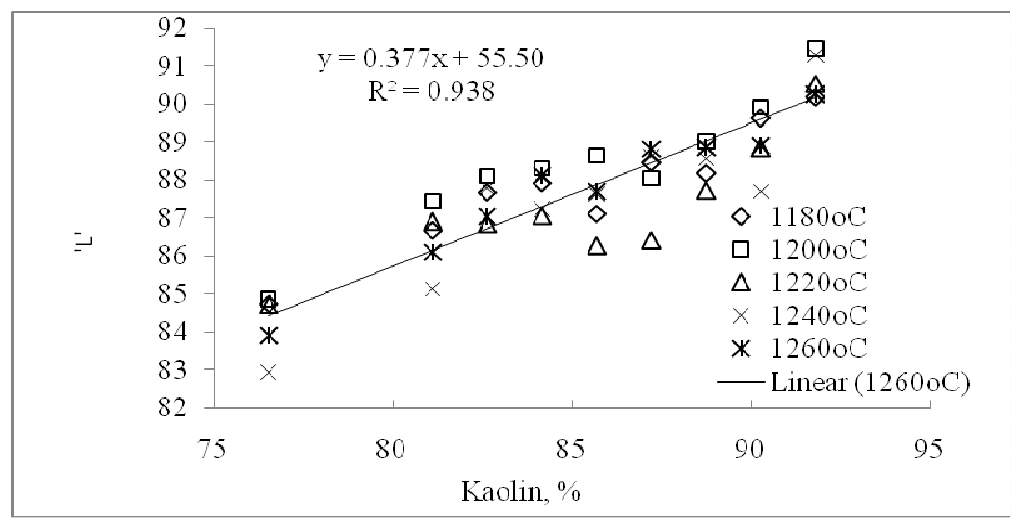

Fig. 5: Plot of 'L' values v/s Kaolin content for clay only specimen

Plot of 'a' with respect to kaolin, haematite and rutile presented in Fig. 6, 7 and 8 showed varying trends with confidence level fluctuating between $87 \%$ to $98 \%$, however above $1240^{\circ} \mathrm{C}$, the confidence level remained greater than $90 \%$. 


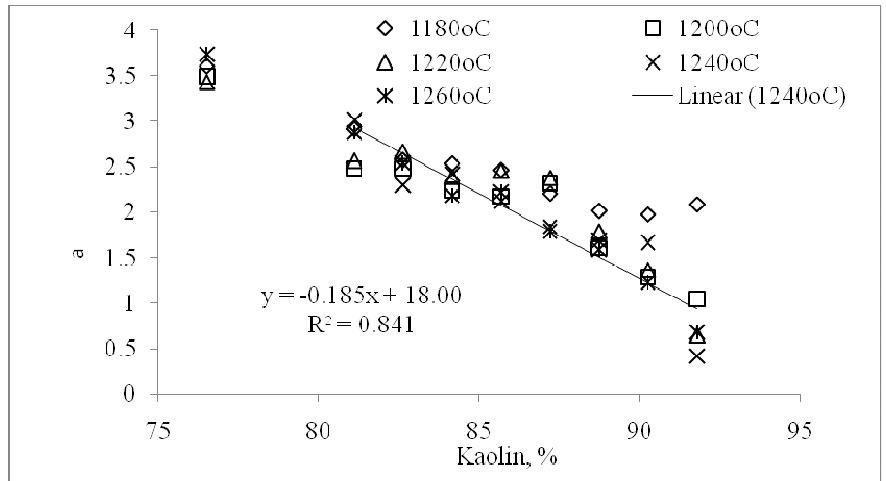

Fig. 6: Plot of 'a' values v/s Kaolin content for clay only specimen

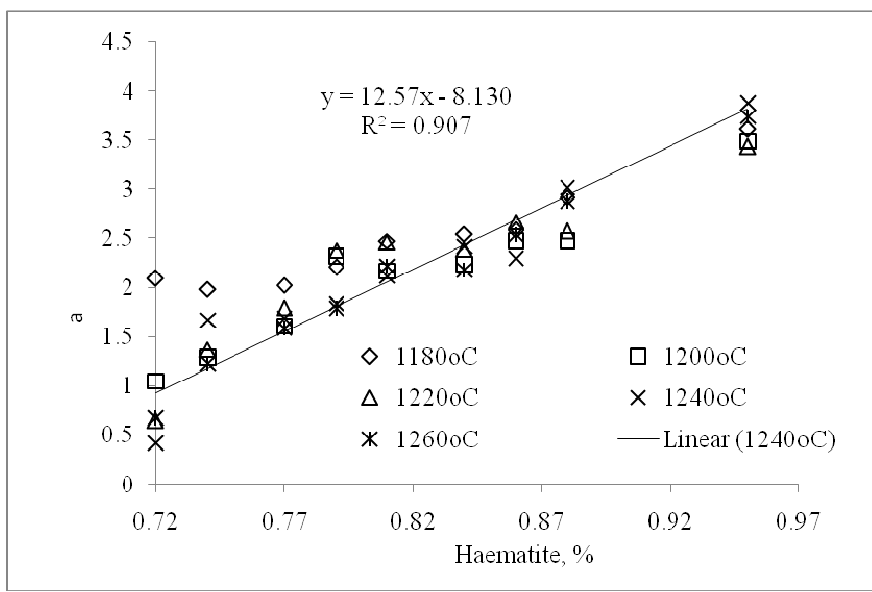

Fig. 7: Plot of 'a' values v/s Haematite content for clay only specimen

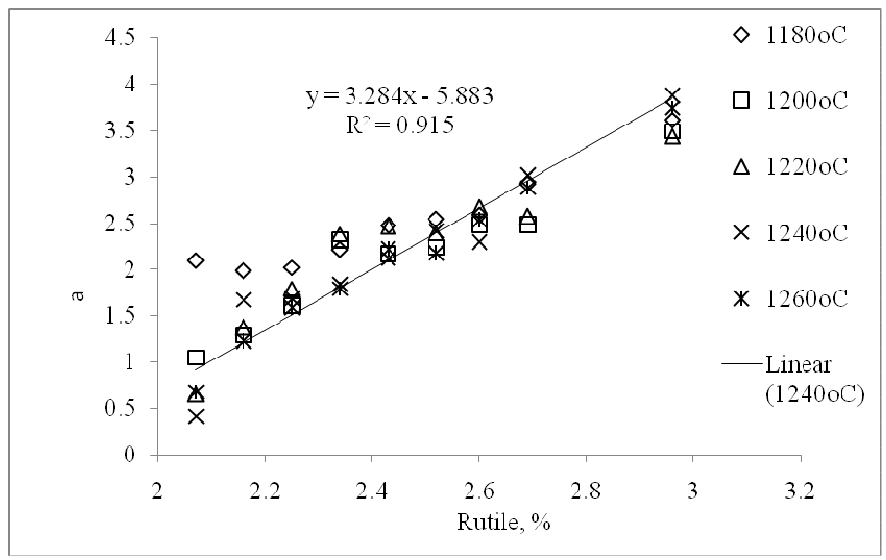

Fig. 8: Plot of 'a' values v/s Rutile content for clay only specimen 
Plot of ' $b$ ' values with different fix parameters did not yield any trend (Fig. 9). Plot of 'ISO2470' with respect to 'kaolin content' showed maximum confidence level of $87 \%$ only at $1260^{\circ} \mathrm{C}$ (Fig. 10).

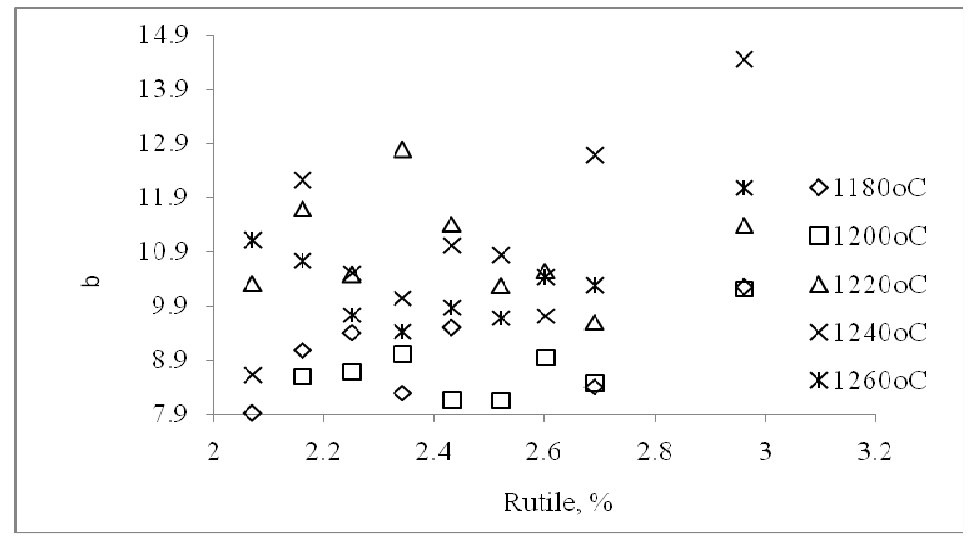

Fig. 9: Plot of 'b' values v/s Rutile content for clay only specimen

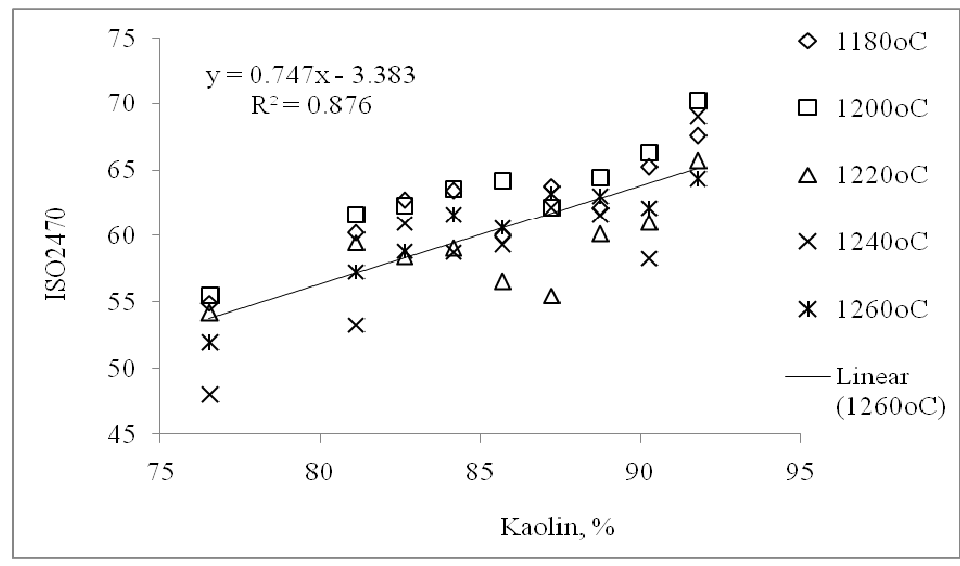

Fig. 10: Plot of 'ISO2470' values v/s Kaolin content for clay only specimen

For 'clay and feldspar' samples, plot of 'L' versus Kaolin content (Fig. 11) showed the ' $L$ ' values to vary with kaolinite content linearly with a confidence level of greater than $95 \%$ on all the firing temperatures $\geq 1220^{\circ} \mathrm{C}$. Plot of ' $\mathrm{L}$ ' vs Haematite (Fig. 12) and ' $\mathrm{L}$ ' vs Rutile (Fig. 13) showed $92.4 \%$ and $94.3 \%$ confidence level at $1220{ }^{\circ} \mathrm{C}$. Plot of 'ISO2470' values with respect to kaolin content (Fig. 14) showed confidence level of $91.7 \%, 92.9 \%$ and $91.3 \%$ at firing temperatures of $1220^{\circ} \mathrm{C}, 1240^{\circ} \mathrm{C}$ and $1260^{\circ} \mathrm{C}$ respectively. Plot of 'b' values (Fig. 15) and 'redness' values (Fig. 16) against kaolin, haematite or rutile etc. did not show any adequate trends. 


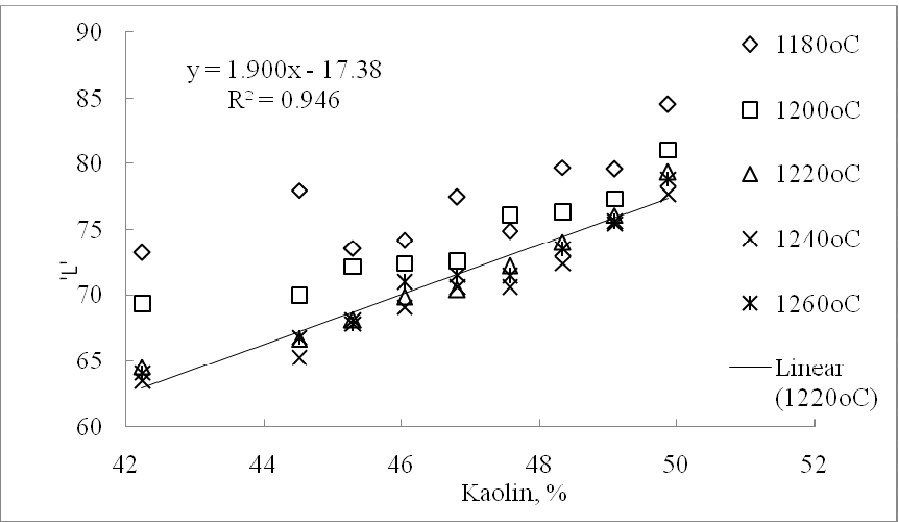

Fig. 11: Plot of 'L' values v/s Kaolin content for 'Clay and Feldspar' specimen

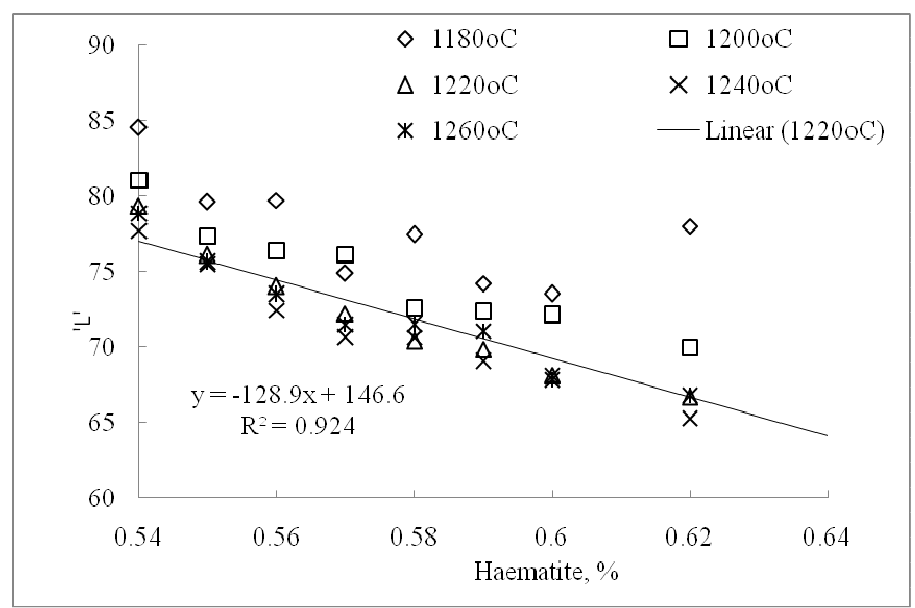

Fig. 12: Plot of ' $L$ ' values v/s Haematite content for 'Clay and Feldspar' specimen.

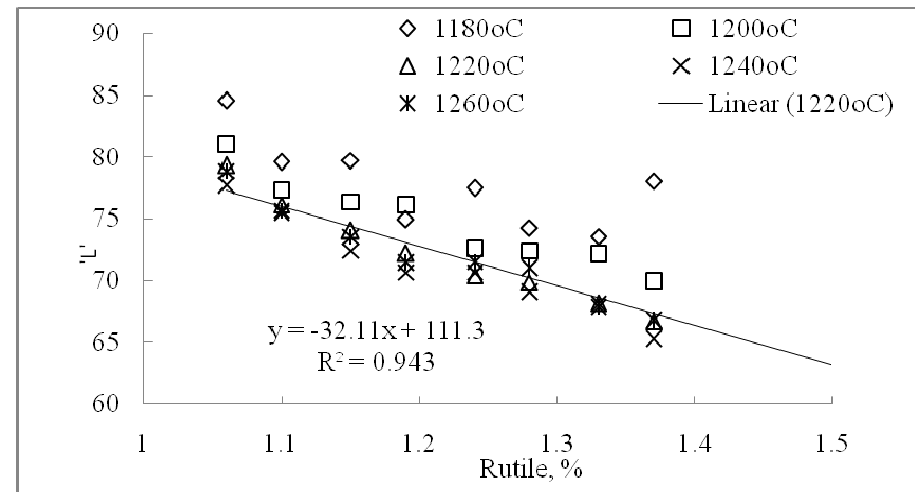

Fig. 13: Plot of 'L' values v/s Rutile content for 'Clay and Feldspar' specimen. 


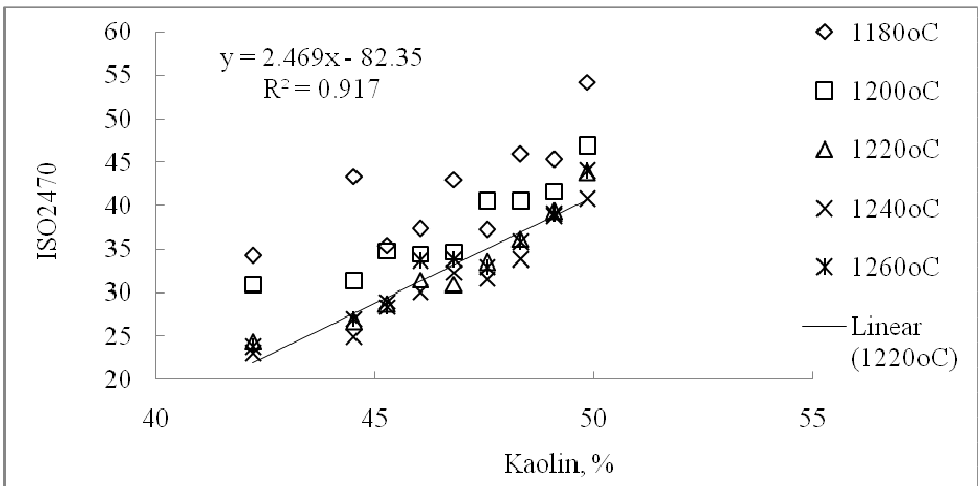

Fig. 14: Plot of 'ISO2470' values v/s Kaolin content for 'clay and felspar' specimen.

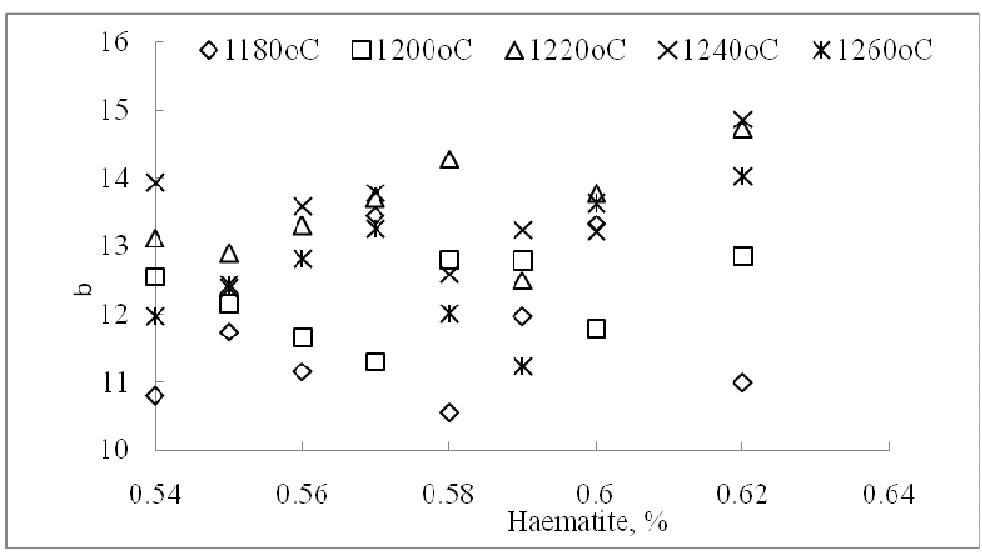

Fig. 15: Plot of 'b' values v/s Haematite content for 'clay and felspar' specimen.

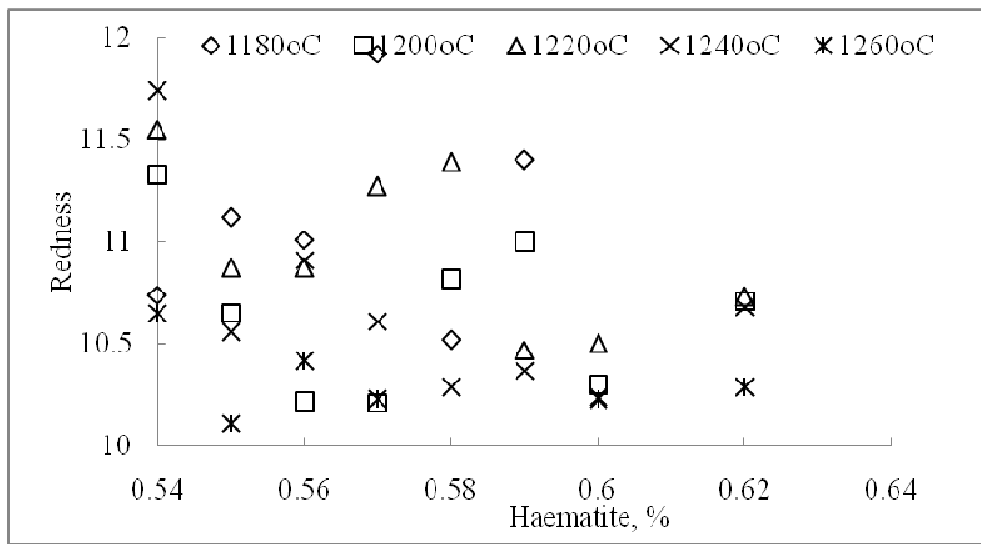

Fig. 16: Plot of 'Redness' values v/s Haematite content for 'clay and felspar' specimen. 


\section{Conclusion}

1. Based on above discussion it is inferred that the variation in colour values of kaolin clay specimens after firing is not linear exactly.

2. The colour values obtained by spectrophotometer of clay only specimens after firing represent the chromophore impurity present therein in a less reliable manner. These values may be misleading if different types of clays are compared.

3. The colour values of $\mathrm{L}$, a and ISO2470 of clay specimens obtained in vitreous condition truly represent the chromophore impurity present therein.

4. To relatively estimate the quantity of chromophore impurity present in a clay sample with its fired colour, the sample should be mixed with $50 \%$ by weight of potash feldspar, pressed in to tablet suitable for colour measurement and fired at or above $1220 \circ \mathrm{C}$ so as to vitrify. After that the ' $\mathrm{L}$ ', ' $\mathrm{a}$ ' and 'ISO2470' values obtained truly represent the chromophore present therein.

\section{Acknowledgments}

The authors are thankful to the Director, CGCRI, Kolkata for his constant encouragement and permission to publish the paper. Authors are also thankful to chemical laboratory, Material Characterization Lab, and XRD division (Kolkata) for their co-operation for various testing activities in connection to this study.

\section{References}

1. Stevenson, B. The colour measurement of ceramic samples using a commercial colour measuring device and a laboratory spectrophotometer,. $\mathrm{PhD}$ desertation, University of Eddinburgh., Eddinburgh, 2009.

2. Sathy Chandrashekhar, S. R., Influence of mineral impurities on the properties of Kaolin and its thermally treated products. Applied clay science 2002, 21, 133-142.

3. P Raghavan, S. C., V.Vogt, E.Gock Separation of titanoferrous impurities from kaolin by high shear pretreatment and froth flotation. Applied clay science 2004, 25, 111-120.

4. J. A. Gonzalez, M. D. C. R., Bleaching of kaolins and clays by chlorination of iron and titanium. Applied clay science 2006, 33, 219-229.

5. S. Chandrashekhar, Influence of metakaolinisation temperature on the formation of Zeolite A4 from kaolin. clay minerals 1996, 31, 253-261.

6. Stoch, L., Iron in Kaolins; Mineralogical, crystallo-chemical and technological aspects. Interceramics 1987, 6, 21-25. 